Original Article

\title{
EVALUATION OF PIGMENTS AS ANTIOXIDANT AND ANTIBACTERIAL AGENTS FROM BETA
} VULGARIS LINN.

\author{
MARIYA SAANI*, REENA LAWRENCE \\ Department of Chemistry, Sam Higginbottom Institute of Agriculture, Technology and Sciences (Formerly AAI-DU), Allahabad, India \\ 211007 \\ Email: mariaya.saani@gmail.com
}

Received: 27 Dec 2016, Revised and Accepted: 20 Mar 2017

\begin{abstract}
Objective: The work is aimed to evaluate the health beneficial properties of (Beta vulgaris) Beetroot. Beetroot ranks among the 10 most powerful vegetable as a natural antioxidant and has a potential source of natural food colourant. The present work is therefore organized to evaluate the Total Phenolic Content (TPC), Antioxidant activity and Antibacterial activity of the Ethanolic and Methanolic extracts of Beetroot.

Methods: In the present work the Total Phenolic Content was determined by using Folin-Ciocalteu reagent method of the Ethanolic and Methanolic extracts of Beetroot (Beta vulgaris). The antioxidant scavenging activity of these extracts was determined by applying three different assay methods: (1) (1, 1-diphenyl-2-picryl hydrazyl) DPPH method, (2) Ferric thiocyanate (FTC) method and (3) Thiobarbituric acid (TBA). The antibacterial test was examined against gram positive (B. subtilis, S. aureus) and gram negative (E. coli, S. dysenteriae) bacterial strains.

Results: In the present work the Methanolic extract showed greater TPC value $394.8 \mathrm{mg} / \mathrm{g}$ GAE than the Ethanolic extract $316.8 \mathrm{mg} / \mathrm{g}$ GAE. A correlation between antiradical capacities of the extracts with TPC value was clearly observed. The Methanolic extract was found to be most effective in all the methods. $50 \%$ scavenging power of the Methanolic and Ethanolic extracts were $(0.129 \mathrm{mg} / \mathrm{ml}$ and $0.254 \mathrm{mg} / \mathrm{ml})$ in DPPH method respectively. Moreover, in TBA and FTC method, both the extracts of Beetroot exhibited strong percentage inhibition ranging from 49\%-62\%. The results of the antibacterial test indicated that the Ethanolic and Methanolic extracts of Beetroot are significantly effective, both in Gram-negative (E. coli, S. dysenteriae) and in Gram-positive (B. subtilis, S. aureus) bacterium.
\end{abstract}

Conclusion: Thus, from the above experimental observations, it can be clearly stated that the Beetroot is a promising source of natural antioxidant and antibacterial agent and definitely provides an alternative towards synthetic antioxidant because of its beneficial properties.

Keywords: Beetroot, Total phenolic content, Antioxidant, Antibacterial

(C) 2017 The Authors. Published by Innovare Academic Sciences Pvt Ltd. This is an open access article under the CC BY license (http://creativecommons.org/licenses/by/4.0/) DOI: http://dx.doi.org/10.22159/ijcpr.2017v9i3.18884

\section{INTRODUCTION}

In biological systems a variety of naturally occurring compounds and their association with the prevention in various ailments like cardiovascular diseases, liver, kidney disorders, chronic diseases and certain forms of cancer have been investigated and several studies have shown that diet rich in fresh food and vegetables like carrot, beetroot, tomato, grapes, Spanish, green tea, garlic and turmeric etc. provide a shield against degenerative diseases [1-4].

In the recent years, natural compounds isolated from several plants have attracted the focus of researchers for their medicinal and dietary values. There are a large group of naturally occurring compounds including vitamin $\mathrm{A}$, vitamin $\mathrm{E}$, vitamin $\mathrm{C}$, plant pigments like betalain, carotenoids, flavonoids, phenolic acids and polyphenols which possess the capability to regulate our cellular metabolism, and maintain the oxidative balance in our body and retard many diseases linked to the oxidative stressed such as cancer, diabetes, nervous disorders, heart diseases etc. and play a significant role as an antioxidant, antiviral, antimicrobial, hepatoprotective and anti-cancerous agent [5-7].

Plant pigments and phenolic compounds have been studied and found to possess a free radical and ROS (reactive oxygen species like superoxide radical ion, singlet oxygen, hydroxyl radical, hydrogen peroxide, etc.) scavenging power and thus act as natural antioxidant either by termination of free radical chain reaction or by reduction of ROS and other free radical species of the biological system, which are generated during the oxidative stress conditions and are responsible for serious damages of macromolecules(like protein, lipid, DNA), peroxidation of food, many harmful diseases and aging $[8,9]$.

Beetroot (Beta vulgaris) is a member of Chenopodiaceae family. It is originally found in South Europe as an annual or biennial herb and is extensively cultivated in Europe, Russia, America, and Asia. It has been listed as one of the most beneficial vegetables due to its higher percentage of antioxidant activity in addition to its great application in the food industry with respect to the presence of a natural colourant Betalain [10, 11].

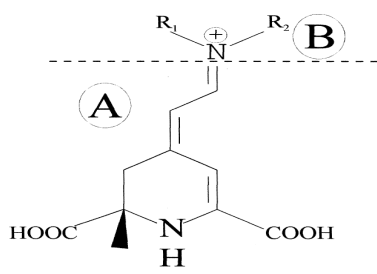

Betalain general formula (A) Betalamic acid moiety (B) The structure will be betacyanin or betaxanthin depending on the residue $\mathrm{R} 1$ and $\mathrm{R} 2$.

Red Beet Betalain pigment comprises an excellent natural food colourant and is effective against the oxidative stress and act as a scavenger of the free radical and ROS species which are associated with the many diseases [12]. It is a nitrogenous pigment, soluble in water and synthesised from amino acid Tyrosine. It is composed of two units Betacyanin (red-violet) and Betaxanthin (yellow). The basic structure of betacyanin consists of condensation of betalamic acid with cyclodopa which may be glycosylated with a sugar moiety, further, condensation of betalamic acid with amines or amino acid gives betaxanthin [13-15]. So far, it has been found that more than 50 betacyanins are reported and the most important is Betanin (5-0$\beta$-glucoside) which is responsible for the color in beetroot and have 
been used as a natural colourant in the modern food industry $[16,17]$. Along with the betanin, betalain also consists of isobetanin, neobetanin, betanidin, vulgaxanthin (I), and vulgaxanthin (II) and all acts as scavengers of free radical and ROS species $[18,19]$.

Besides this, beetroot contains about a one-tenth portion of pure sugar which are glucose, glucuronic acid or apiose. Moreover, it has been to be found that beetroot contains a significant amount of phenolic acids like chlorogenic acid, caffeic acid, ferulic acid, cinnamic acid and p-coumaric acid in addition to small amount of vitamin $\mathrm{A}$, vitamin C, vitamin B12, iron, potassium, sodium, zinc and calcium [20-22]. The abundance of statements has been established suggesting that the beetroot is not only used as a harmless natural food colorant but also plays a major role in the reduction of oxidative stress because of its antioxidant ability. It is potentially believed to be associated with antioxidant, anti-inflammatory, antimicrobial, hepatoprotective activities [23-27].

The present study is thus designed to focus on the examination of antioxidant activity of Beet Root extracts (ethanol and methanol) using three different methods and antibacterial activity along with the evaluation of total phenolic content spectrophotometrically.

\section{MATERIALS AND METHODS}

\section{Plant material}

Beetroot (Beta vulgaris) were collected from local markets of Allahabad, Uttar Pradesh, India and identified in the post graduated department of Horticulture, SHIATS. Allahabad. The beetroot was cleaned and cut into small pieces and was subjected to dry at room temperature. The dried root was grinded and powdered.

\section{Preparation of extracts}

The $60 \mathrm{~g}$ of dried and powdered plant material were extracted with $150 \mathrm{ml}$ of solvent ethanol and then with methanol by using soxhlet extractor for $48 \mathrm{~h}$ at a temperature not exceeding the boiling point of the solvents. The extracts were filtered by using Whatman No. 1 paper. The extracts were concentrated to a small volume by using rotary evaporator then concentrated to dryness and were used for further investigation.

\section{Total phenolic content (Folin-ciocalteu method)}

Total phenolic content in the extracts was determined using FolinCiocalteu method [28]. For this, $0.1 \mathrm{ml}$ of stock solution $(1 \mathrm{mg} / \mathrm{ml})$ of the extract was mixed with $0.75 \mathrm{ml}$ of Folin-Ciocalteu reagent $(1 \mathrm{ml}$ in $10 \mathrm{ml}$ of DW.) and left to stand for $5 \mathrm{~min}$. After which $0.75 \mathrm{ml}$ of aqueous Sodium Carbonate $(100 \mathrm{mg} / \mathrm{ml})$ was added and the volume of the reaction mixture was made up to $10 \mathrm{ml}$ by adding distilled water. The mixture was allowed to incubate for $90 \mathrm{~min}$. The standard curve was prepared using different dilutions of Gallic acid $(2,1,0.5,0.25,0.125,0.0625 \mathrm{mg} / \mathrm{ml})$. The absorbance was taken at $760 \mathrm{~nm}$ using UV-VIS Spectrophotometer. The total phenolic values were calculated and expressed in terms of milligrams of Gallic acid per $10 \mathrm{ml}$ of extract.

\section{Antioxidant activity}

\section{DPPH radical scavenging activity assay}

The antioxidant activity of the extracts was measured by using stable radical $\mathrm{DPPH}^{-}$as a reagent and the activity was determined in terms of hydrogen donating and electron releasing abilities of the extracts. The different working solutions of the extracts were prepared in methanol $(1,0.5,0.25,0.125,0.0625 \mathrm{mg} / \mathrm{ml})$. The DPPH solution $(0.002 \%)$ was also prepared in methanol. In each of the test-tubes different concentration of the extract was taken and the made up the volume to $2 \mathrm{ml}$, to this was added $2 \mathrm{ml}$ of DPPH solution and test tubes were then incubated for $30 \mathrm{~min}$ at room temperature. The same procedure was followed for BHT and Gallic acid as well. Methanol with DPPH was used as a control. The method given above is the same as used by Kahalaf [29]. With slight modification. The absorbance was recorded at $517 \mathrm{~nm}$ using a UV-Visible spectrophotometer. The radical scavenging activity of each extract was calculated by using the following equation-

(\%) Scavenging effect $=[1-(\mathrm{A} / \mathrm{B})] \mathrm{X} 100$

\section{Where \\ $A=$ absorbance of the sample \\ $\mathrm{B}=$ absorbance of the control}

\section{Ferric thiocyanate method}

The FTC Method was used to determine the antioxidant activity of extracts [30]. $4 \mathrm{mg}$ of each extract was dissolved in $4 \mathrm{ml}$ of ethanol (99.5\%), to it was mixed $4.1 \mathrm{ml}$ of linoleic acid $(2.5 \%$ in ethanol 99.5\%), $8 \mathrm{ml}$ of Phosphate Buffer $(0.02 \mathrm{M}, \mathrm{pH} 7)$ and $3.9 \mathrm{ml}$ of distilled water. The mixture was then incubated at $40 \mathrm{oC}$ in an oven. After this, $9.7 \mathrm{ml}$ of ethanol (75\%) and NH4SCN (30\%) was added to $0.1 \mathrm{ml}$ of the reaction mixture to measure the extent of the antioxidant activity. After 3 minutes of the addition of $0.1 \mathrm{ml}$ of ferrous chloride $(0.02 \mathrm{M})$ in $3.5 \% \mathrm{HCl}$ to the reaction mixture, the absorbance was measured at $500 \mathrm{~nm}$ using UV-Visible Spectrophotometer. The absorbance was taken at every $24 \mathrm{~h}$ until the maximum value of control absorbance was obtained. BHT was used as standard here. The inhibition of lipid peroxidation was measured as follows-

(\%) Inhibition $=100-\left[\left(A_{1} / A_{0}\right) \times 100\right]$

Where

$\mathrm{A}_{0}=$ absorbance of the control reaction mixture

$A_{1}=$ absorbance of the sample reaction mixture

\section{Thiobarbituric acid method}

The TBA test has been conducted according to Huda-faujan [30]. In this method, $2 \mathrm{ml}$ of Trichloroacetic Acid (20\%) and $2 \mathrm{ml}$ of Thiobarbituric Acid (67\%) were added to $1 \mathrm{ml}$ of the sample that was prepared for FTC Method and the solution kept on water bath for $10 \mathrm{~min}$ at $100^{\circ} \mathrm{C}$, it was then cooled and centrifuged at 3000 rpm for $20 \mathrm{~min}$. The absorbance of supernatant was measured at $532 \mathrm{~nm}$. The antioxidant activity has been described by percentage inhibition-

(\%) Inhibition $=\left[1-\left(\mathrm{A}_{1} / \mathrm{A}_{0}\right)\right] \times 100$

Where

$\mathrm{A}_{1}=$ absorbance of the sample

$\mathrm{A}_{0}=$ absorbance of the control

\section{Antibacterial activity}

For the evaluation of antibacterial activity of the Beet root against some bacterial strains, agar well diffusion method was used [31]. The bacterial strains used in this study including gram-positive Staphylococcus aureus, Bacillus subtilis and gram-negative Escherichia coli, Shigella dysenteriae were obtained from the Laboratory of Microbiology and Fermentation Technology, SHIATS, Allahabad, India. $20 \mu \mathrm{l}$ volume of the sample extracts of $2 \mathrm{mg} / \mathrm{ml}$ concentration poured into $5 \mathrm{~mm}$ well of inoculated agar plates. Ampicillin $10 \mathrm{mg} / \mathrm{ml}$ was used as a positive control. The resulting zone of inhibition (ZI) were measured after the incubation of $48 \mathrm{~h}$ at $370 \mathrm{C}$ and expressed in $\mathrm{mm}$. The antibacterial activity results were considered as inactive if $<4.5 \mathrm{~mm} ; 4.5-6 \mathrm{~mm}$ as partially active; while $6.5-9 \mathrm{~mm}$ as active and greater than $9 \mathrm{~mm}$ as very active [32]. The experiments were carried out in triplicate and averaged.

\section{RESULTS AND DISCUSSION}

\section{Total phenolic content of the extract}

The antioxidant activities of plants may be attributed to the Phenolic compounds due to their redox properties. These are secondary plant metabolites and contribute to the plant's antioxidant ability.

Folin-Ciocaltue method was used to determine the TPC of Beetroot extracts using Gallic Acid as the standard. The TPC was calculated with a regression equation based on a standard curve using Gallic acid at different concentration $\left(y=0.077 x, R^{2}=0.998\right)$ and expressed in milligrams of Gallic acid. From fig. 1, it could be interpreted that methanolic extract had the greater Phenolic concentration of 394.8 
$\mathrm{mg} \mathrm{GAE} / \mathrm{mg}$ followed by an ethanolic extract which was $316.8 \mathrm{mg}$ GAE/mg. Aris [33] reported that the TPC in fruits of Ficus Deltoidea Var Angustifolia ranges from 159.2-259.2 mg/g GAE. Moringaolifera has TPC value in three different climates (India, Nicaragua and Niger) ranged from 2940-4250 mgGAE/dry weight [34].

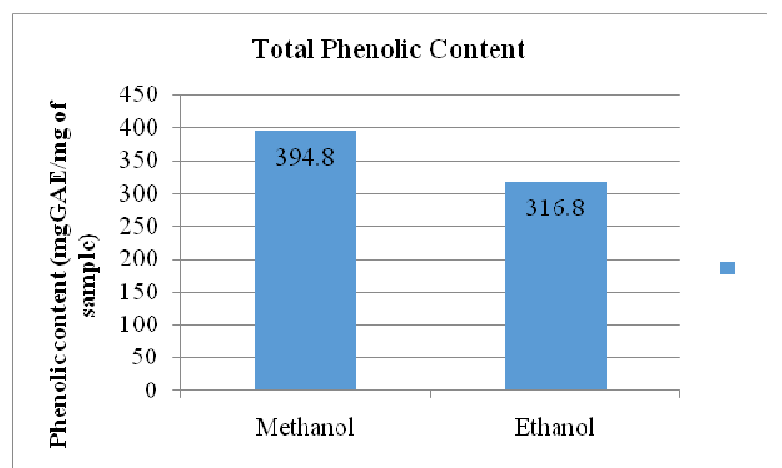

Fig. 1: Total phenolic content in ethanol and methanol extracts of Beetroot

\section{Antioxidant activity}

\section{DPPH radical scavenging activity assay}

In this study, the scavenging activity was determined by the DPPH testing method, which was found to be rapid, easy and economical for measurement antioxidant activity [35-37]. The DPPH ${ }^{-}$is a free radical, stable in nature and accepts an electron or hydrogen radical to become a stable molecule. The reducing nature of $\mathrm{DPPH}^{*}$ was determined by a decrease in its absorbance induced by antioxidants at $517 \mathrm{~nm}$. In the $\mathrm{DPPH}^{-}$method, all the results were obtained from the extracts of Beetroot and were compared with Gallic acid and BHT taken as standard references. As illustrated in fig. 2 scavenging of $\mathrm{DPPH}^{\prime}$ increases with increase in the extract concentration. The $\mathrm{IC}_{50}$ value is defined as the concentration of the extract at which $50 \%$ of radicals have been scavenged under experimental conditions. A smaller IC 50 value corresponds to higher antioxidant activity [38]. In this study, highest DPPH scavenging activity was shown by methanolic extract with IC $50 v a l u e ~ 0.129 \mathrm{mg} / \mathrm{ml}$ and by ethanolic extract with $\mathrm{IC}_{50}$ value $0.254 \mathrm{mg} / \mathrm{ml}$.

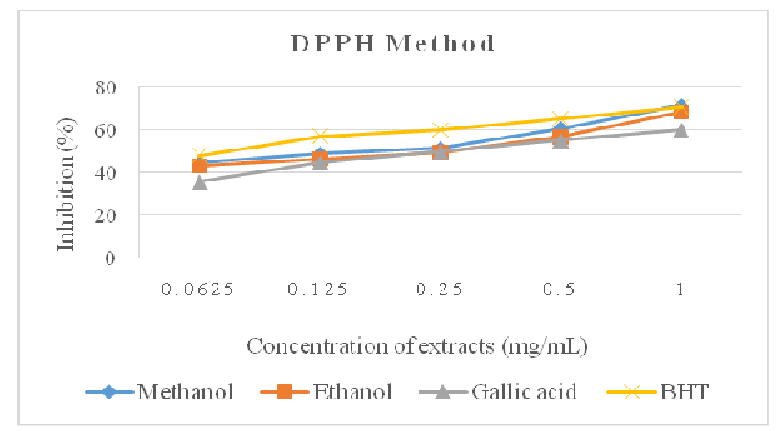

Fig. 2: DPPH scavenging activity of ethanol and methanol extracts of Beet root and standards BHT and Gallic acid with different concentration $(\mathrm{mg} / \mathrm{ml})$

\section{Ferric thiocyanate method}

The amount of peroxide value in the beginning of liquid peroxidation was measured by the FTC method, where ferric ions are formed upon reaction of peroxide with ferrous chloride. The ferric ions then unite with ammonium thiocyanate producing ferric thiocyanate, it is red in color. The darker the color, the higher will be the absorbance [35]. Lower absorbance correlates to high antioxidant activity [33]. In FTC method, both the methanolic and ethanolic extract of beetroot had been oxidized when stored for seven days and exhibited strong antioxidant potential in inhibiting linoleic acid oxidation as compared to the control. From the fig. 3, the percentage of inhibition of linoleic acid of ethanolic extract, methanolic extract and BHT were found to be $51 \%, 62 \%$ and $69 \%$ respectively. The absorbance of control was 0.410 after seven days of storage. Initially, the highest percent inhibition is shown by methanolic extract (62\%) and ethanolic exhibited the lower percent inhibition (51\%) than methanol extract. Huda et al., 2009 reported the percentage of linoleic acid inhibition of $P$. koenigii, C. Caudatus, $C$. asiatica, 0 . javanica, and $P$. minus to be $70.60,68.67,66.17,65.41$ and $63.66 \%$ respectively. The antioxidant activity also increases with increase in the concentration of the plant extract.

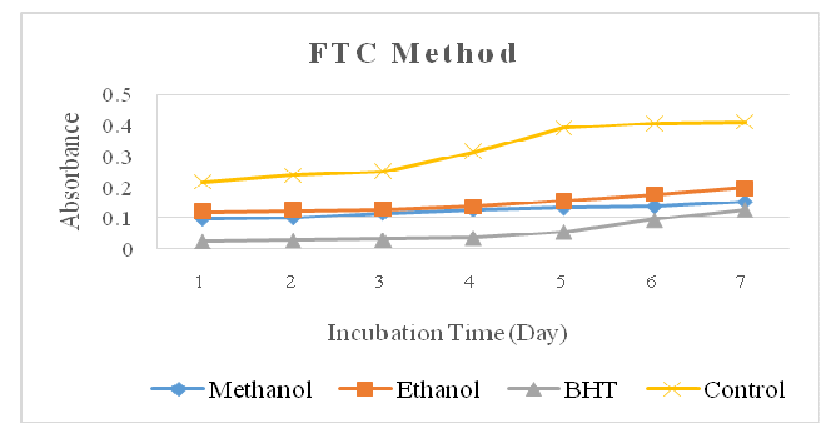

Fig. 3: Antioxidant activity of ethanol, methanol extracts of Beet root and standard BHT as measured by the FTC method

\section{Thiobarbituric acid method}

TBA method is used to measure the extent of lipid peroxidation at the secondary stage where peroxide decomposes to form carbonyl compounds. Both the extracts showed strong antioxidant activities. The percentage of antioxidant activities of methanolic extract and ethanolic extract and BHT were 58\%, 49\% and 65\% respectively. The absorbance of control sample obviously showed the highest reading. This result is similar to that reported by Huda-faujan [30] and Aris [33] that the control sample had the highest absorbance reading in TBA after seven days of storage. Fig. 4 shows that the amount of peroxide in the initial stage of lipid peroxidation is greater than the amount of peroxide present in the secondary stage.

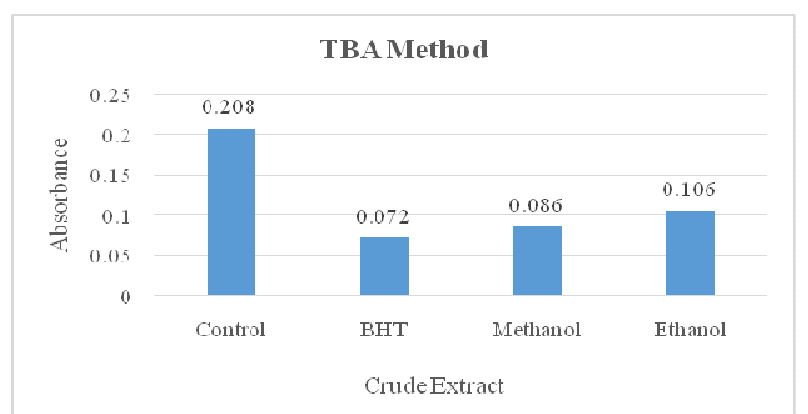

Fig. 4: Antioxidant activity of ethanol, methanol extracts of Beet root and Standard BHT as measured by the TBA method

\section{Antibacterial activity}

Along with this activity in vitro antibacterial activity of ethanolic and methanolic extracts of Beetroot was examined by using agar well diffusion method. According to the result given in fig. 5, methanolic extract exhibits strong activity against both gram positive and gram negative strains and showed the highest activity against $B$ subtilis with $18.2 \mathrm{~mm}$ ZI. On the other hand, ethanolic extract showed weak antibacterial activity that was comparable with the standard. 
Methanolic and ethanolic extracts exhibited antibacterial activity in descending order $B$. subtilis $>S$. aureus $>E$. coli $>S$. dysenteriae. This result have a similar observation with that of TPC as the methanolic extract possessed higher phenolic content than ethanolic extract. Thus Beetroot extracts could be used as an effective antibacterial agent.

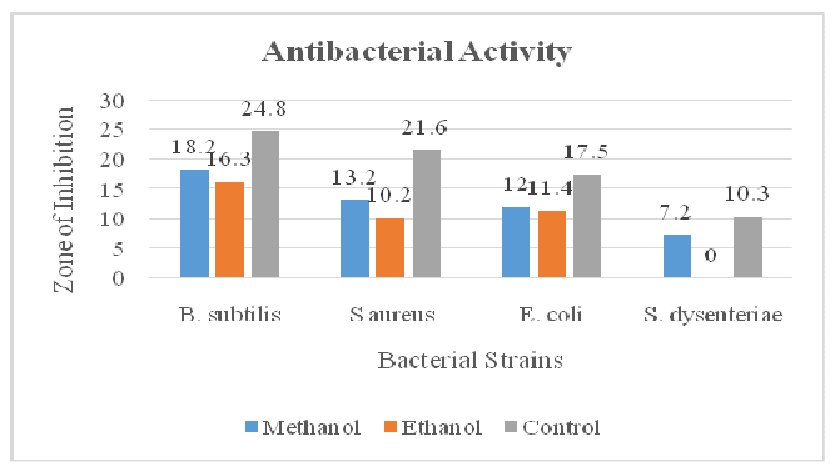

Fig. 5: Antibacterial activity of ethanol and methanol extracts of Beetroot (values are mean SD of three determinations)

Natural antioxidants are found to be powerful scavengers of ROS, and significantly provide healthy lifestyle along with the degree of protection towards various diseases in human body system [39]. Natural antioxidants advance over the synthetic antioxidant due to their non-toxic nature. Drugs based on the application of antioxidant for the protection of complex diseases like diabetes, stroke, cancer, heart and kidney damages have attracted a great deal of researchers towards the use of natural antioxidants. Much plant extracts exhibit efficient antioxidant properties due to their phytoconstituents including phenolic pigments like carotenoid, flavonoids, betalains, small amounts of vitamins and ions. [40, 41].

The present study supports the scavenging activity and antibacterial potential of the beet root extracts. In the food industry, potentially safe natural antioxidants have been isolated from beetroot. This study has shown that the methanolic and ethanolic extracts of beetroot possess a considerable amount of phenolic compounds and exhibit a positive correlation between the antioxidant, antibacterial activity and total phenolic content.

Formation of the non-radical form of DPPH (DPPH-H) obtained by the reduction of $\mathrm{DPPH}^{-}$in the presence of radical scavengers or hydrogen donors present in plants extracts provides the basis of antiradical activity on DPPH radical scavenging assay. The measurement of antiradical activity was achieved by the application of the series of different concentrations of ethanolic and methanolic extracts of beetroot. The result shows that methanolic extract possesses strong antioxidant activity with $\mathrm{IC}_{50} 0.129 \mathrm{mg} / \mathrm{ml}$ which was greater than that shown by ethanolic extract with $\mathrm{IC}_{50} 0.254$ $\mathrm{mg} / \mathrm{ml}$. Both the extracts prove themselves to be a potential antioxidant.

Methanolic and ethanolic extracts of beetroot were examined by FTC and TBA methods. The amount of peroxide formed at initial stages of linoleic acid peroxidation would be measured by FTC method. The antioxidant activity increases as the concentration of peroxide decreases when stored for seven days. The determination of evaluation of the extent of lipid peroxidation was done by the TBA method through measurement of the secondary products of oxidation like aldehyde and ketone. Initially, the control sample showed highest absorbance reading and lower level of antioxidant activity as compared to both the extracts and standards. Based on the absorbance rate, the methanolic extract possessed prominent antioxidant activity with $62 \%$ and $58 \%$ followed by ethanolic extract with $51 \%$ and $49 \%$ for FTC and TBA methods respectively. The beetroot extracts showed potential activities against the Gram positive and Gram negative bacteria such as, $B$. subtilis, $S$. aureus, E. coli and $S$. dysenteriae. The methanolic and ethanolic extracts prepared from the beetroot are effective against enterobacterial growth. Our results agree with the previous studies that show that the beetroot has significant activity against various pathogenic and opportunistic bacteria.

In this present work, after cumulating the results, it could be considered that the beet root extracts might be a potent source of antioxidant and possesses a high antibacterial potential of preventing and treating diseases like malaria, stroke, diabetes, heart diseases and cancer.

\section{CONCLUSION}

From the above experimental observations, it can be clearly stated that the beetroot is a promising source of natural antioxidant and antibacterial agent and definitely provides an alternative towards synthetic antioxidant because of its beneficial properties and opens a new aspect of research trend for beetroot as a natural antioxidant and viable food ingredient.

\section{ACKNOWLEDGEMENT}

I would like to express my deepest appreciation to all those who provided me the possibility to complete this report. A special gratitude I give to our guide, Dr. Reena Lawrence research supervisor whose contribution in stimulating suggestions and encouragement helped me to coordinate my work.

\section{CONFLICT OF INTERESTS}

Declare none

\section{REFERENCES}

1. Anesini C, Ferraro GE, Filip R. Total polyphenol content and antioxidant capacity of commercially available Tea (Camellia sinensis) in Argentina. J Agric Food Chem 2008;56:9225-9.

2. Aqil F, Ahmad I, Mehmood Z. Antioxidant and free radical scavenging properties of twelve traditionally used Indian Medicinal Plants. Turkish J Biol 2006;30:177-83.

3. Karou D, Dicko MH, Simpore J, Traore AS. Antioxidant and antibacterial activities of polyphenols from ethnomedicinal plants of Burkina Faso. Afr J Biotechnol 2005;4:823-8.

4. Yadav N, Vasudeva N, Singh S, Sharma SK. Medicinal properties of genus Chenopodium Linn. Indian J Nat Prod Resour 2007;6:131-4.

5. Huda-Faujan N, Noriham A, Norrakish AS, Babji AS. Antioxidative activity of water extract of some Malaysian herbs. Asian Food J 2007;14:61-8.

6. Jamaludin M, Chou TY, Azrina ZA. Total phenolic content of selected fruits and vegetables commonly found locally in Malaysia. Rev Global Med Healthcare Res 2010;1:81-8.

7. Jocob SJP, Shenbagaraman S. Evaluation of antioxidant and antimicrobial activity of the selected leafy vegetables. Int J Pharm Tech Res 2011;3:148-52.

8. Dianzami MU. The role of free radical in liver damage. Proc Nutr Soc 1987; 46:43-52.

9. Koppenol WH. Free radical damage and its control. Elsevier science Publication company, Inc. New York; 1994. p. 3-24.

10. Dlim MM, Alsabri SG, Mohamad SS, Zetrini AE, Salem AAH, Auzi AA. Use of Beta vulgaris as a natural colouring agent for food and cosmetics in Libya. J Chem Pharm Res 1994;5:340-5.

11. Canadanovic-Brunet JM, Savatovic SS, Cetkovic GS, Vulic JJ, Dililas SM, et al. Antioxidant and antibacterial activities of Beet root Pomace extract. Czech J Food Sci 2011;29:575-85.

12. Gliszezynska-swigo A, Szymusiak H, Malinowska P. Betalain, The main pigment of red beet-molecular origin of its exceptionally high free radical-scavenging activity. Food Addit Contam 2006;23:1079-87.

13. Cai YZ, Sun M, Corke H. Characterisation and application of betalain pigment from a plant of Amaranthaceae. Trends Food Sci Technol 2005;16:370-6.

14. Woo KK, Fanny-Wong FN, Catherine Chua HS, Tang PY. Stability of spray dried pigment of Red dragon fruit [Hylocereus polyrhizus weber Britton and Rose] as a function of organic acid additives and storage condition. Philippine Agric Sci 2011;99:264-9.

15. Zou D, Brewer M, Gracia F, Feugang JM, Wang J, Zang R. Cactus pear; a natural product in cancer chemoprevention. Nutr J 2005;4:25-36. 
16. Azeredo HM. Betalain: properties, sources, applications and stability-a review. Int J Food Sci Technol 2009;44:2365-76.

17. Slavov A, Karagyozov V, Denev P, Kratechanova M, Kratechanov C. Antioxidant activity of red beet juice obtained after microwave and thermal pretreatments. Czech J Food Sci 2013;31:139-47.

18. Tanaka Y, Sasaki N, Ohmiya A. Biosynthesis of plant pigment: anthocyanins, betalains and carotenoids. Plant J 2008;54:733-49.

19. Sakac MB, Pericin DM, Mandic AI, Kormanjos SM. Antioxidant properties of Ethanolic extract of sugar Beet root pulp. Original Sci Paper 2004;35:355-264.

20. Git MI, Ferreres F, Tomas-Barberan FA. Effect of modified atmosphere packaging on the flavonoids and vitamin $C$ content of minimally processed swiss chard (Beta vulgaris subspecies cycla.). J Agric Food Chem 1998;46:2007-12.

21. Nemzer B, Pietrzkowski Z, Sporna A, Stalica P, Thresher W, Michalowski $\mathrm{T}$, et al. Betalain and nutritional profiles of pigment enriched red Beetroot (Beta vulgaris $L$.) dried extracts. Food Chem 2011;127:42-53.

22. Ogan A, Korsilayan-Kuzu H, Demir S, Gencer odner BO, Gunel A, Enginum M. Investigation of Red beet (Beta vulgaris L.) Juice proteins for vitamin $B_{12}$ binding. J Fac Pharm Istanbul 2004;37:77-81.

23. Chakole $\mathrm{R}$, Zade $\mathrm{S}$, Charde $\mathrm{M}$. Antioxidant and antiinflammatory activity of ethanolic extract of Beta vulgarislinn root. Int J Biomed Adv Res 2011;2:124-30.

24. Kapur A, Sati S, Ranjan A, Gupta P. Screening methanolic extract of Beta vulgaris roots for photoprotective activity. Int J Pharm Pharm Sci 2012;4:124-7.

25. Kim I, Chrin YW, Lim SW, Kim YC, Kim J. Norisoprenoids and Hepatoprotective Flavone glycosides from the aerial parts of Beta vulgaris. Archibes Pharmacal Res 2004;27:600-3.

26. Koubaier HBH, Essaidi I, Snoussi A, Zyoulli S, Chaabouni MM, Thonart $\mathrm{P}$, et al. Effect of Saccharomyces cerevisiae fermentation the colorant of heated red beet root extracts. Afr J Biotechnol.2013;12:728-34.

27. Shyamala BN, Jamuna P. Nutritional content and antioxidant properties of pulp waste from Daucus carota and Beta vulgaris. Malaysian Journal of Nutrition.2010;16:114-121.

28. Velioglu YS, Mazza G, Gao L, Oomah BD. Antioxidant activity and total phenolics in selected fruits, vegetables, and grain products. J Agric Food Chem 1998;46:4113-7.
29. Khalaf NA, Shakya A, Al-olhman A, El-Agbar Z, Farah H. Antioxidant and anti-inflammatory activity of an Ethanolic extract of Beta-vulgaris linn roots. Turkish J Biol 2008;32:51-5.

30. Huda-Faujan N, Noriham A, Norrakish AS, Babji AS. Antioxidant activity of plant methanolic extracts containing phenolic compounds. Afr J Biotechnol 2009;8:484-9.

31. Perez C, Pauli M, Bazevque P. An antibiotic assay by the agar well diffusion method. Acta Biol Med Exp 1990;15:113-5.

32. Junior A, Zanil C. Biological screening of Brazalian medicinal plants. J Braz Sci 2000;95:367-73.

33. Aris SRS, Mustafa S, Ahmat N, Jaafar FM, Ahmad R. Phenolic content and antioxidant activity of fruits of Ficus Deltoidea Varangustifoliaspe. Malaysian J Agric Sci 2009;13:146-50.

34. Sidduraju P, Becker K. Antioxidant properties of various solvent extracts of total phenolic constituents from three different agroclimatic origins of drumstick tree. (Moringa oleifera lam) leaves. J Agric Food Chem 2003;51:2144-55.

35. Chang LW, Yen WJ, Huang SC, Duh PD. Antioxidant activity of sesame coat. Food Chem 2002;78:347-54.

36. Duh PD, Tu YY, Yen GC. Antioxidant activity of water extract of Harny Jyur (Chrysanthenum morifolium ramat). Food Sci Technol 1999;32:269-77.

37. Rahman MM, Fazlic V, Saad NW. Antioxidant properties of raw Garlic (Allium sativum) extract. Int Food Res J 2012;19:589-91.

38. Cuvelier ME, Richard H, Berset C. Comparison of the antioxidant activity of some acid phenol: structures activity relationships. Biosci Biotechnol Biochem 1992;56:324-5.

39. Naphade SS, Khadabadi SS, Derore SL, Jagtap NS, Hadke SP. Antioxidant activity of different extracts of plant Tricholepis Glaberrima D. C. (Asteraceae). Int J Pharma Tech Res 2009;1:502-5.

40. Tariq AL, Riyaz AL. Antioxidant activity of Camellia sinensis leaves. Int J Curr Microbiol Appl Sci 2013;2:40-6.

41. Bajpai M, Panday A, Tiwari SK, Prakash D. Phenolic content and antioxidant activity of some food and medicinal plant. Int J Food Sci Nutr 2005;56:284-91.

\section{How to cite this article}

- Mariya Saani, Reena Lawrence. Evaluation of pigments as antioxidant and antibacterial agents from beta vulgaris linn. Int J Curr Pharm Res 2017;9(3):37-41. 